\title{
An Electrical Energy Consumption Monitoring and Forecasting System
}

\author{
J. L. Rojas-Renteria \\ Engineering Dpt, \\ Autonomous \\ University \\ of Queretaro, Mexico \\ luis_rojasr@ \\ hotmail.com
}

\author{
T. D. Espinoza-Huerta \\ Faculty of Accounting \\ and Administration, \\ Autonomous University \\ of Queretaro, Mexico \\ tdespinoza@ \\ mail.itq.edu.mx
}

\author{
F. S. Tovar-Pacheco \\ Industrial Maintenance and \\ Construction Dpt, \\ Technological University of \\ San Juan del Rio, Mexico \\ fstovarp@ \\ utsjr.edu.mx
}

\author{
J. L. Gonzalez-Perez \\ Linking Dpt, \\ Polytechnic University \\ of Santa Rosa Jauregui, \\ Mexico \\ gpjluismx@ \\ hotmail.com
}

\author{
R. Lozano-Dorantes \\ Engineering Dpt, \\ Anahuac University \\ Mexico \\ raullozanodorantes@ \\ hotmail.com
}

\begin{abstract}
Electricity consumption is currently an issue of great interest for power companies that need an as much as accurate profile for controlling the installed systems but also for designing future expansions and alterations. Detailed monitoring has proved to be valuable for both power companies and consumers. Further, as smart grid technology is bound to result to increasingly flexible rates, an accurate forecast is bound to prove valuable in the future. In this paper, a monitoring and forecasting system is investigated. The monitoring system was installed in an actual building and the recordings were used to design and evaluate the forecasting system, based on an artificial neural network. Results show that the system can provide detailed monitoring and also an accurate forecast for a building's consumption.
\end{abstract}

Keywords-power consumption; energy monitoring; heuristic methods

\section{INTRODUCTION}

The problem of electric energy consumption, and its forecast, is an issue of growing interest. The growth in industrial, commercial and housing sectors result in increased electricity consumption whereas the nature of the loads has shifted towards a nonlinear nature. However, the overall consumption of buildings is lately recognized as an important characteristic, now increasingly considered and implemented in the building's calculated worth. In this situation, new challenges surfaced. The energy efficiency of electrical and control devices is constantly sought to be improved [1], but the most significant means of optimization are related to the power network (generation, transmission, distribution) [2]. Of course, the optimization of the network is of great interest to power companies. Nowadays, the distribution companies need to monitor and correct problems in energy quality for the benefit of their users, real-time plot the average values of the programmed energy production and make adjustments according to the demand of the day [3]. Thus, detailed consumption monitoring systems is of great interest to power distribution companies.
However, it has also proved to be valuable for consumers. The energy profile of buildings is now increasingly considered during the buildings' design and the overall reduction in energy consumption results to increased power quality [6-7]. Further, close monitoring may be used by consumers to alter their consumption routine and thus exploit flexible rates provided by power companies and general reduce their consumption. Recent research has shown that the traditional periodic measurements have been ineffective in changing users' behavior. However, detailed monitoring (and electronic feedback) has been more efficient in that area [4]. In [5], it was concluded that close monitoring captures the attention of the audience, gains participation and it is credible and useful to users. Although it is not simple to unfold the information, what matters the most at this stage is that these information motivates consumers to save energy.

In [8], a study regarding the benefits of an interactive connection information system of energy consumption for residential buildings was conducted. A comparison of energy consumption before and after the installation of the system revealed a reduction in the total consumption of electricity. Information about the energy consumption is also very useful for detecting abnormalities [5]. The next generation of predictive load schemes however, will require an increased amount of information and the ability to make an accurate forecast will be a significant benefit of monitoring systems.

This paper focuses on a system that is able to monitor and forecast the electricity consumption of a building. The forecast part is based on an Artificial Neural Network (ANN) and it uses actual consumption data as recorded from the monitoring system installed in an actual building. Being able to provide accurate forecasts of future consumption is obviously a matter of great importance for power companies. Consumers may also benefit from such a system in the future as smart grids may bring about flexible rates linked to overall consumption thus making an accurate forecast rather useful. 


\section{CONSUMPTION MONITORING}

Technological advances in networking, communications, data management, and measurement technology have combined to reduce significantly the cost of energy monitoring systems (EMS), and to increase the capacity of these systems and include energy quality data. Traditional measuring instruments used individual analog circuits to measure and calculate the energy parameters. A power monitoring system can currently perform all measurements on a single chip. As the level of integration increases, the gauge of the future will be smaller, more capable and less expensive. In [9], a list of intelligent building components is provided, in which power management systems (SAE) are the most important. SAE allows a user to control and monitor energy consumption of a building locally or remotely. For proper operation of a SAE, accurate energy consumption values are necessary [10].

The energy consumption data considered in this paper, were obtained from the main substation at the Technological University of Corregidora from January 29 to November 3, 2015. A building management system (BMS) was designed and installed in the control room of the building, embedded on a web server. This BMS is based on a microcontroller module that allows the monitoring of the building's energy consumption in real time via the Internet (Figure 1). It should be noted that since monetary relations are based on meter readings, production, sale and use of these instruments are subjected to strict regulations and specification. The threephase analyzer used in this system complies with ANSI/ISA S82.01-1994. Figure 2 shows a part of monitoring data obtained.

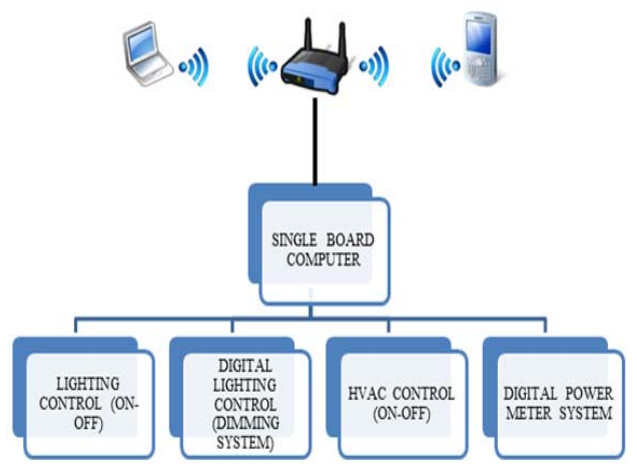

Fig. 1. The BMS scheme

\begin{tabular}{|c|c|c|c|c|c|}
\hline Title & W Full Total & $\mathrm{t}$ & $\min$ & average & $\max$ \\
\hline ID & & $0.00 E+\infty$ & 1.10E+04 & 1. $17 \mathrm{E}+04$ & $1.44 E+04$ \\
\hline Type & MnAvgMax Flagged & $9.00 E+02$ & $9.71 E+03$ & 1. $15 \mathrm{E}+04$ & $1.42 \mathrm{E}+\mathrm{C}$ \\
\hline Date & $06 / 16 / 14$ & $1.80 E+03$ & $9.10 \mathrm{E}+03$ & $9.91 \mathrm{E}+03$ & $1.22 \mathrm{E}+\mathrm{C}$ \\
\hline Time & $12: 37: 40$ & $270 E+03$ & $7.96 E+03$ & $9.44 \mathrm{E}+03$ & $1.30 E+0$ \\
\hline X scale & $7.70 E+04$ & $3.60 E+03$ & $7.96 \mathrm{E}+03$ & 8. $50 E+03$ & $1.21 \mathrm{E}+\mathrm{C}$ \\
\hline$X$ At $0 \%$ & $0.00 E+00$ & $4.50 E+03$ & $7.62 E+03$ & $9.10 \mathrm{E}+03$ & $1.19 E+0$ \\
\hline X Resolution & $8.55 E+01$ & $5.40 E+03$ & $7.55 E+03$ & 8. $.02 E+03$ & $1.02 E+0$ \\
\hline x size & 855 & $6.30 E+03$ & $7.62 \mathrm{E}+03$ & 8. $23 \mathrm{E}+03$ & $1.02 \mathrm{E}+\mathrm{C}$ \\
\hline$x$ Unit & $\mathrm{s}$ & $7.20 E+03$ & $7.35 E+03$ & $7.96 E+03$ & $1.05 E+0$ \\
\hline X Label & $76950 \mathrm{~s} / \mathrm{Div}$ & $8.10 E+03$ & $7.82 \mathrm{E}+03$ & $9.10 \mathrm{E}+03$ & $1.20 E+0$ \\
\hline Y scale & $2.00 E+05$ & $9.00 E+03$ & $6.68 E+03$ & $7.28 E+03$ & $9.64 E+0$ \\
\hline Y At $50 \%$ & $0.00 E+\infty$ & $9.90 E+03$ & $6.68 \mathrm{E}+03$ & $8.09 \mathrm{E}+03$ & $1.19 E+0$ \\
\hline Y Resolution & $2.97 \mathrm{E}+03$ & $108 E+04$ & $7.42 E+03$ & $8.09 \mathrm{E}+03$ & $9.98 E+03$ \\
\hline Y size & 65536 & $11 \pi t+04$ & $7.49 \mathrm{E}+03$ & $8.16 \mathrm{E}+03$ & $9.51 \mathrm{~F}+0$ \\
\hline YUnit & $w$ & $1.26 E+04$ & $7.22 \mathrm{E}+03$ & $8.02 E+03$ & $1.02 \mathrm{E}+\mathrm{C}$ \\
\hline Y Label & $k w$ & $135 E+04$ & $7.28 E+03$ & 8. $02 E+03$ & $1.02 \mathrm{E}+0$ \\
\hline
\end{tabular}

Fig. 2. Measurement of energy monitoring

\section{FORECAST SCHEME AND RESULTS}

The proposed forecasting model is based mainly on an artificial neural network. This network was used to select the best average of the absolute differences between measured and estimated values, expressed as a percentage of the measured values. The ANN implemented in this study is a multilayer perceptron (MLP) with an input layer of 3 nodes (the inputs are $\mathrm{kW}, \mathrm{Hr}$ and day), a hidden layer with a variable number of hidden nodes (several networks with variable number of hidden nodes were implemented and tested) and an output layer with only one node (the result of the forecast).

The basic description of the algorithm is as follows:

- $\quad$ determine the input and output variables

- include a set of data describing the relationship between input-output model

- divide the data set into 2 parts: the training and validation set (used to determine the parameters of the ANN) and the test set (used to evaluate the model). $80 \%$ of the data is used to train the network, $10 \%$ is used for the validation and the remaining $10 \%$ is used for generalization.

- develop a conventional model to train the network with the data set

- $\quad$ estimate the relationship between inputs and outputs of the neural network (i.e. define the ANN).

These steps are repeated to find the appropriate number of hidden nodes, using different training parameters for the network.

The ANN was implemented in Matlab. Several models were evaluated for a structure of 7000 hrs. The error of the mean absolute percentage (MAPE) was used to evaluate the performance of the different ANNs. The results for each tested ANN are shown in Table I. As shown, the 3-3-1 ANN performed best. Figure 3 shows the approximation curve. A data analysis tool called hypothesis testing was employed to accept or reject the found values. A threshold of $95 \%$ confidence level has been set and an added probability factor is considered to make sure that the results are statistically significant. Figure 4 shows a screenshot from the data analysis procedure.

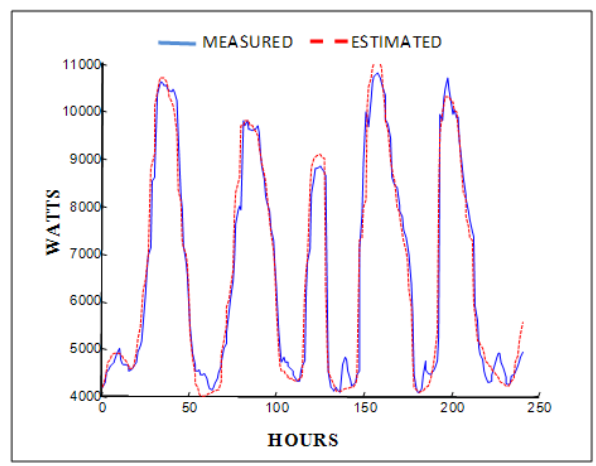

Fig. 3. Approximation curve electricity consumption 
TABLE I. COMPARISON OF THE ESTIMATED ERROR FOR DIFFERENT MODELS OF NEURAL NETWORKS

\begin{tabular}{|c|c|c|c|}
\hline Model & $\mathbf{R}^{2}$ & MAPE & SEP \\
\hline $3-1-1$ & 0.9015 & 0.0628 & 0.0959 \\
\hline $3-2-1$ & 0.9270 & 0.0617 & 0.1788 \\
\hline $3-3-1$ & 0.9310 & 0.0537 & 0.0849 \\
\hline $3-4-1$ & 0.9264 & 0.0563 & 0.1094 \\
\hline $3-5-1$ & 0.9003 & 0.0662 & 0.1134 \\
\hline $3-6-1$ & 0.9153 & 0.0650 & 0.1073 \\
\hline $3-7-1$ & 0.9023 & 0.0631 & 0.1126 \\
\hline $3-8-1$ & 0.9010 & 0.0571 & 0.1094 \\
\hline
\end{tabular}

\section{CONCLUSION}

An electricity consumption forecast system based on an Artificial Neural Network (ANN) is investigated in this paper. Actual values recorded from a monitoring system installed in the main substation of a university building were used to design and evaluate the system. Hypothesis testing was employed and a threshold value of 95\% was used to ensure that the results are statistically significant. Several architectures were tested and the best results showed an estimated error (mean absolute percentage) of 0.0537 .

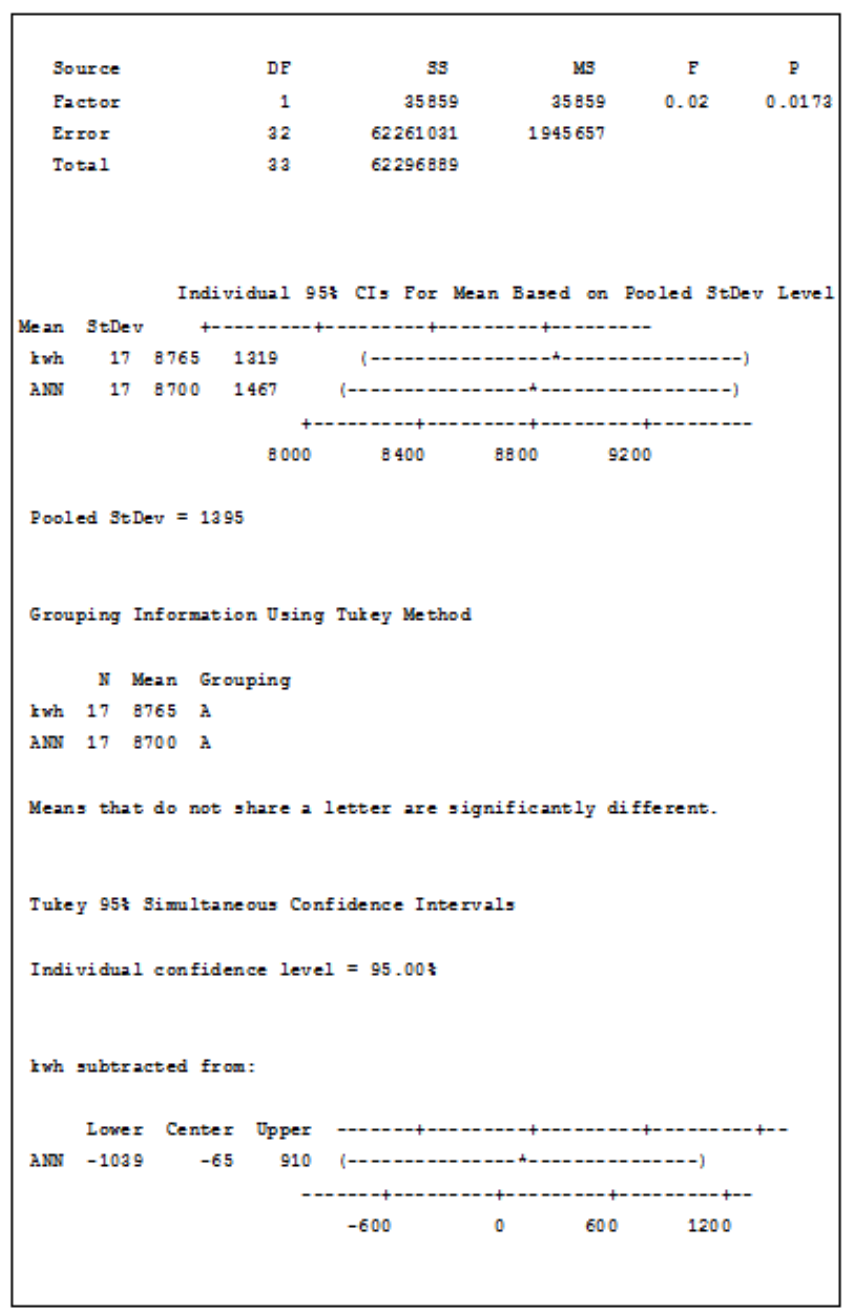

Fig. 4. Data analysis

\section{REFERENCES}

[1] P. Soderholm, "The political economy of international green certificate markets”, Energy Policy,Vol. 36, No. 6, pp. 2051- 2062, 2008

[2] N. Truong, L. Wanga, P. K. C. Wong "Modelling and short-term forecasting of daily peak power demand in Victoria using twodimensional wavelet based SDP models”, Electrical Power and Energy Systems, Vol. 30, pp. 511-518, 2008

[3] J. K. W. Wong, H. Li, S. W. Wang, "Intelligent building research: a review”, Automation in Construction, Vol. 14, pp. 143-159, 2009

[4] G. Wood, M. Newborough, "Energy-use information transfer for intelligent homes: Enabling energy conservation with central and local displays”, Energy and Buildings, Vol. 39, No. 4, pp. 495-503, 2006

[5] J. E. Seem, "Using intelligent data analysis to detect abnormal energy consumption in buildings", Energy and Buildings, Vol. 39, No. 1, pp. 52-58, 2006

[6] J. L. Rojas-Renteria, G. Macias-Bobadilla, R. Luna-Rubio, C. A. Gonzalez-Gutierrez, A. Rojas-Molina, J. L. Gonzalez-Perez "Control response of electric demand by means of fuzzy logic using programmable logic controller (PLC)”, International Journal of Physical Sciences, Vol. 8, No. 20, pp. 1058-1067, 2013

[7] Y. S. Kim, K. S. Kim, "Simplified energy prediction method accounting for part-load performance of chiller”, Building and Environment, Vol. 42, No. 1, pp. 507-515, 2007

[8] J J. L. Rojas-Renteria. R. Luna-Rubio, J. L. Gonzalez-Perez, C. A. Gonzalez-Gutierrez, A. Rojas-Molina, G. Macias-Bobadilla, "Estimated electric power consumption by means of artificial neural networks and autoregressive models with exogenous input methods”, International Journal of Physical Sciences, Vol. 8, No. 14, pp. 585-592, 2013

[9] H. Doukas, K. D. Patlitzianas, K. Iatropoulos, J. Psarras, "Intelligent building energy management system using rule sets", Building and Environment, Vol. 42, No. 10, pp. 3562-3569, 2007

[10] J. K. Pal, F. C. Huff, "Advantages of an electrical control and energy management system”, ISA Transactions, Vol. 39, No. 1, pp. 103-114, 2000

\section{AUTHORS PROFILE}

J. L. Rojas-Rentería received the Ph.D. degree in the Division de Estudios de Posgrado at ES, Autonomous University of Queretaro. received the B.E degree in Automation and Instrumentation in Industrial Processes Control, the M.S. degree in Quality Engineering from the Engineering School (ES), Autonomous University of Queretaro (UAQ). He joined the ES as Assistant Professor in 2010 and at the Technological University of Corregidora as a research professor in 2012. He has 22 years of experience in different types of industrial mechanic and electric maintenance, as well as industrial machinery facilities. His current research interests are focused on building management systems for Intelligent Buildings, control of energy demand response, and forecasting of electrical power energy.

T. D. Espinoza-Huerta is a research professor in the Department of Industrial Engineering from the Technological Institute of Queretaro and Autonomous University of Queretaro.

F. S. Tovar Pacheco is a Director of the Division of Production Systems, Industrial Maintenance and Construction of the Technological University of San Juan del Rio.

J. L. Gonzalez-Perez is a Software Engineer and Software Quality Consultant (Software Testing and Audit Processes). He has worked with Capability Maturity Model Integration (CMMI), model for the improvement and evaluation of processes for development, maintenance and operation of software systems. He has worked as a research Professor at the Polytechnic University of Santa Rosa Jauregui (UPSRJ) and other universities in Mathematics, Computer Algorithms, Embedded Software, Expert Systems, Computer Vision and Digital Image Processing.

R. Lozano-Doantes received a Master's degree from the Department of Engineering and Control of Process of the Autonomous University of Queretaro. His research interests include develop computational and control of process of multivariable tank, evolutionary computation, time series of this modeling prototipe and control numeric of drill automatic forecasting, and develop of machinery bend process and welding. 